\title{
Thyroid hormones act indirectly to increase sex hormone-binding globulin production by liver via hepatocyte nuclear factor-4 $\alpha$
}

\author{
David M Selva ${ }^{1,2}$ and Geoffrey L Hammond ${ }^{1,2}$ \\ ${ }^{1}$ Child and Family Research Institute, 950 West 28th Avenue, Vancouver, British Columbia, Canada V5Z 4H4 \\ ${ }^{2}$ Department of Obstetrics and Gynaecology, The University of British Columbia, 4500 Oak Street, Vancouver, British Columbia, Canada V6H 3N1 \\ (Correspondence should be addressed to G L Hammond; Email: ghammond@cw.bc.ca)
}

\begin{abstract}
Thyroid hormones increase hepatic sex hormone-binding globulin (SHBG) production, which is also regulated by hepatocyte nuclear factor- $4 \alpha(\mathrm{HNF}-4 \alpha)$ in response to changes in the metabolic state of the liver. Since the human SHBG promoter lacks a typical thyroid hormone response element, and because thyroid hormones influence metabolic state, we set out to determine whether thyroid hormones mediate SHBG expression indirectly via changes in HNF- $4 \alpha$ levels in HepG2 human hepatoblastoma cells, and in the livers of transgenic mice that express a $4.3 \mathrm{~kb}$ human $S H B G$ transgene under the control of its own $0.8 \mathrm{~kb}$ promoter sequence. Thyroid hormones (triiodothyronine $\left(T_{3}\right)$ and thyroxine $\left(T_{4}\right)$ ) increase SHBG accumulation in HepG2 cell culture medium over 5 days, and increase cellular SHBG mRNA levels. In addition, $\mathrm{T}_{4}$ treatment of HepG2 cells for 5 days increased HNF-4 $\alpha$ mRNA and HNF-4 $\alpha$ levels in concert with decreased cellular palmitate levels. Plasma SHBG levels were also increased in mice expressing a human SHBG transgene after 5 days treatment with $\mathrm{T}_{3}$ along with increased hepatic HNF-4 $\alpha$ levels. In HepG2 cells, the human SHBG promoter failed to respond acutely (within $24 \mathrm{~h}$ ) to $\mathrm{T}_{4}$ treatment, but a 4-day pre-treatment with $\mathrm{T}_{4}$ resulted in a robust response that was prevented by co-treatment with HNF- $4 \alpha$ siRNA, or by blocking the $\beta$-oxidation of palmitate through co-treatment with the carnitine palmitoyltransferase I inhibitor, etomoxir. These data lead us to conclude that thyroid hormones increase SHBG production indirectly by increasing $H N F-4 \alpha$ gene expression, and by reducing cellular palmitate levels that further contribute to increased HNF-4 $\alpha$ levels in hepatocytes.
\end{abstract}

Journal of Molecular Endocrinology (2009) 43, 19-27

\section{Introduction}

Thyroid hormones influence plasma sex hormonebinding globulin (SHBG) levels under both normal and pathological conditions (Anderson 1974) by altering the production of SHBG by hepatocytes (Rosner et al. 1984). In addition, blood levels of SHBG in infants increase within the first 2-3 weeks after birth, and this has been attributed to a postnatal maturation of hepatic sensitivity to thyroid hormones (Leger et al. 1990). Plasma SHBG levels are also commonly elevated beyond normal reference ranges in patients with hyperthyroidism (Anderson 1974), but are not increased in individuals suffering from familial thyroid hormone resistance, despite their very high blood levels of thyroid hormones (Sarne et al. 1988). Since the latter is likely due to defects in thyroid hormone action in the liver, it has been proposed that plasma SHBG measurements can be used clinically to assess end-organ sensitivity to thyroid hormones (Sarne et al. 1988).

Human HepG2 hepatoblastoma cells have been widely used as a model for the studies of thyroid hormone action in the liver (Rosner et al. 1984, Raggatt et al. 1992, Kester et al. 2006). These cells express the type I iodothyronine deiodinase that converts the prohormone thyroxine $\left(\mathrm{T}_{4}\right)$ into the receptor-active triiodothyronine $\left(\mathrm{T}_{3}\right)$ in the normal liver, but they lack the type III iodothyronine deiodinase: a key enzyme responsible for deactivating thyroid hormones in the liver and other tissues (Kester et al. 2006). On the other hand, HepG2 cells express the glucuronidases responsible for the metabolic clearance of thyroid hormones in the liver (van Stralen et al. 1996). The human $S H B G$ gene is also expressed in HepG2 cells and their production of SHBG is enhanced by thyroid hormone treatments in concert with an increase in SHBG mRNA levels (Rosner et al. 1984, Mercier-Bodard et al. 1991, Raggatt et al. 1992).

In earlier studies, increases in plasma SHBG have been noted in hypothyroid patients several days after the initiation of treatment with $\mathrm{T}_{3}$ (Sarne et al. 1988), and this is consistent with studies in which treatment of HepG2 cells with thyroid hormones increase SHBG production after 2-3 days (Rosner et al. 1984, Raggatt et al. 1992). It has been assumed that these responses are mediated directly by the thyroid hormone receptor 
(TR) acting at the level of the human $S H B G$ gene. Thyroid hormones exert their effects at the gene level via the TR, which generally binds as a heterodimer with the retinoid $\mathrm{X}$ receptor to cis-acting elements that are referred to as thyroid hormone response elements (TREs) within target gene promoters. A typical TRE is a tandem repeat of the consensus AGGTCA separated by four nucleotides (Zhang \& Lazar 2000), and is classified as a direct repeat-4 (DR-4) element. It was therefore of interest that a bioinformatic scan failed to identify a DR-4-like element that might act as a TRE within the human $S H B G$ promoter responsible for controlling its expression in the liver (Jänne \& Hammond 1998).

Since thyroid hormones influence the metabolic state of the liver (Malik \& Hodgson 2002) and because we have recently demonstrated that $S H B G$ gene expression in hepatocytes is dynamically regulated by changes in their metabolic state (Selva et al. 2007), we set out to determine whether thyroid hormoneinduced changes in the metabolic state of HepG2 cells and the liver could account for changes in $S H B G$ expression.

\section{Materials and methods}

\section{Cell culture experiments}

Cell culture reagents were from Life Technologies Inc. (Invitrogen). HepG2 hepatoblastoma cells (catalog no. HB-8065; ATCC, Manassas, VA, USA) were routinely maintained in DMEM supplemented with 10\% FBS and antibiotics (100 $\mathrm{U}$ penicillin/ml and $100 \mu \mathrm{g}$ streptomycin $/ \mathrm{ml}$ ). For experiments, HepG2 cells were cultured to $30-50 \%$ confluence prior to the addition of supplements: glucose (Sigma-Aldrich Canada Ltd), $\mathrm{T}_{3}$ (Sigma-Aldrich), $\mathrm{T}_{4}$ (Sigma-Aldrich) or etomoxir (Sigma-Aldrich), as indicated. Palmitate levels in HepG2 cells were determined as described previously (Selva et al. 2007).

Transient transfections of human $S H B G$ promoterdriven luciferase reporter plasmids together with a pCMVlacZ control plasmid (Jänne \& Hammond 1998, Selva et al. 2007) were performed using the HiPerfect Transfection Reagent (Qiagen). The siRNA experiments were carried out using HiPerfect Transfection Reagent together with either a control siRNA (catalog 1022076) or an hepatocyte nuclear factor- $4 \alpha$ (HNF-4 $\alpha$ ) siRNA (catalog 00161546) obtained from Qiagen. Two days after transfection, the cells were washed twice with PBS and harvested by scraping. After centrifugation, cell pellets were resuspended in $100 \mu \mathrm{l} 250 \mathrm{mM}$ Tris-Cl, $\mathrm{pH} 7 \cdot 8$, and cells were lysed by three freeze-thaw cycles. Appropriate aliquots of cell extracts were used for measurements of luciferase and $\beta$-galactosidase activity.
To correct for transfection efficiency, light units from the luciferase assay were divided by the OD reading from the $\beta$-galactosidase assay.

\section{SHBG measurements}

Human SHBG levels in culture medium taken from HepG2 cells were measured using a time-resolved immunofluorometric assay (Niemi et al. 1988).

\section{RNA analysis}

Total RNA was extracted from HepG2 cells using TRIzol reagent (Invitrogen). Reverse transcription (RT) was performed at $42{ }^{\circ} \mathrm{C}$ for $50 \mathrm{~min}$ using $3 \mu \mathrm{g}$ of total RNA and $200 \mathrm{U}$ of Superscript II together with an oligo(dT) primer and reagents provided by Invitrogen. An aliquot of the RT product was amplified in a 35- $\mu$ l reaction using PCR SuperMix (Invitrogen) with appropriate oligonucleotide primer pairs corresponding to human HNF-4 $\alpha$ (forward primer 5'-GCTCCTCCTTC TGCTGCTGC and reverse primer 5'-GGAAGAGCTT GAGACAGGCC), SHBG (forward primer 5'-GTTGCT ACTACTGCGTCACAC and reverse primer $5^{\prime}$-GCC ATCTCCCATCATCCAGCCG), TR1- $\alpha$ (forward primer $5^{\prime}$-CCGCACAATCCAGAAGAACC and reverse primer 5'-GGCAATGTGGATCAGATCCC), and cyclophilin A (forward primer 5'-ATGGTCAACCCCACCGTG and reverse primer $5^{\prime}$-TGCAATCCAGCTAGGCATG). The PCR was performed for 40 cycles at $94{ }^{\circ} \mathrm{C}$ for $15 \mathrm{~s}$, $57-65{ }^{\circ} \mathrm{C}$ for $30 \mathrm{~s}$, and $72{ }^{\circ} \mathrm{C}$ for $1 \mathrm{~min}$, and PCR products were resolved by electrophoresis in a $1 \%$ agarose gel.

\section{Treatment of human SHBG transgenic mice with thyroid hormone}

Mice that express a $4.3 \mathrm{~kb}$ human $S H B G$ transgene in the liver (Jänne et al. 1998) were routinely maintained on standard laboratory chow and water provided ad libitum. The human SHBG transgene in these mice is expressed in the liver under the control of its own $\sim 800 \mathrm{bp}$ promoter sequence that corresponds to the same sequence we have studied in the context of a luciferase reporter gene (Jänne \& Hammond 1998, Selva et al. 2007). For the experiment, female mice $(n=3)$ were treated with water (controls) or water containing $\mathrm{T}_{3}(0.5 \mathrm{mg} / \mathrm{l})$ for 5 days. Blood samples were taken by saphenous vein sampling for measurements of plasma SHBG levels (Selva et al. 2007) immediately before the treatment, and on day 5 of treatment when livers were also taken for RNA and protein extraction (see below). Animals were weighed before and after treatment and no change in weights were observed in either group over 
the 5 days of treatment. This animal protocol was approved by the Animal Use Subcommittee of the University Council on Animal Care at The University of British Columbia.

\section{Total cellular and nuclear protein extracts}

After treatments, mouse livers or HepG2 cells were harvested and homogenized in $50 \mathrm{mM}$ Tris- $\mathrm{HCl}$, pH $7 \cdot 9,300 \mathrm{mM} \mathrm{KCl}, 1.5 \mathrm{mM} \mathrm{MgCl}_{2}, 0 \cdot 1 \%$ Nonidet P-40, and $20 \%$ glycerol supplemented with Complete protease inhibitor cocktail (Roche Diagnostics) at $4{ }^{\circ} \mathrm{C}$, followed by centrifugation $\left(11000 \mathrm{~g}\right.$ at $\left.4{ }^{\circ} \mathrm{C}\right)$ for $10 \mathrm{~min}$ to obtain total protein extracts. For nuclear protein extracts, the HepG2 cells were first incubated on ice for $10 \mathrm{~min}$ with hypotonic buffer $(10 \mathrm{mM}$ HEPES, pH 7.9, $1.5 \mathrm{mM} \mathrm{MgCl}_{2}, 10 \mathrm{mM} \mathrm{KCl}, 1 \mathrm{mM}$ EDTA, $1 \mathrm{mM}$ EGTA, $0.5 \mathrm{mM}$ dithiothreitol (DTT), $0.2 \mathrm{mM}$ phenylmethylsulfonyl fluoride (PMSF), and the Complete protease inhibitor cocktail). Samples were then homogenized and centrifuged at $2000 \mathrm{~g}$ for $10 \mathrm{~min}$. Pellets were vortex mixed in resuspension buffer (20 mM HEPES, pH 7.9, $240 \mathrm{mM}$ sucrose, $10 \mathrm{mM} \mathrm{KCl}, 1 \mathrm{mM}$ EDTA, $1 \mathrm{mM}$ EGTA, $0.5 \mathrm{mM}$ DTT, $0.2 \mathrm{mM}$ PMSF, and Complete protease inhibitor cocktail) and centrifuged through a $3 \mathrm{ml} 1 \mathrm{M}$ sucrose pad for $1 \mathrm{~h}$ to obtain nuclei. The nuclei were recovered in $200 \mu \mathrm{l}$ resuspension buffer followed by the slow addition of $100 \mu \mathrm{l}$ nuclei isolation buffer $(20 \mathrm{mM}$ HEPES, pH 7.9, $240 \mathrm{mM}$ sucrose, $1.2 \mathrm{M} \mathrm{KCl}, 1 \mathrm{mM}$ EDTA, $1 \mathrm{mM}$ EGTA, $0.5 \mathrm{mM}$ DTT, $0.2 \mathrm{mM}$ PMSF, and Complete protease inhibitor cocktail) and further centrifugation $\left(15000 \mathrm{~g}\right.$ at $\left.4{ }^{\circ} \mathrm{C}\right)$ for $30 \mathrm{~min}$ to obtain a nuclear extract, which was dialyzed overnight against $20 \mathrm{mM}$ Tris, $\mathrm{pH} 7 \cdot 9,100 \mathrm{mM} \mathrm{KCl}, 1 \mathrm{mM}$ EDTA, $1 \mathrm{mM}$ EGTA, and $0.5 \mathrm{mM}$ DTT containing $10 \%$ glycerol.

\section{Western blot analysis}

Total cell protein and nuclear protein extracts were used for western blotting with antibodies against human HNF-4 $\alpha$ (C-19; catalog sc-6556; Santa Cruz Biotechnology Inc., Santa Cruz, CA, USA) and human cyclophilin A (SA-296; BIOMOL Int., Plymouth Meeting, PA, USA). Specific antibody-antigen complexes were identified using an HRP-labeled goat anti-rabbit $\operatorname{IgG}$ or rabbit anti-goat IgG and chemiluminescent substrates (Pierce Biotechnology Inc., Rockfort, IL, USA) by exposure to X-ray film.

\section{Statistical analyses}

Data were analyzed using one-way ANOVA, and $P$ values of $<0 \cdot 05$ were considered significant.

\section{Results}

\section{Thyroid hormones only increase SHBG production by HepG2 cells after 2 days of treatment}

We first examined the effects of daily supplementation with $\mathrm{T}_{3}(100 \mathrm{nM})$ or $\mathrm{T}_{4}(100 \mathrm{nM})$ on SHBG production by HepG2 cells over the course of 5 days, by comparing medium concentrations of SHBG on days 1 and 5 of thyroid hormone treatments. This showed that $\mathrm{T}_{3}$ and $\mathrm{T}_{4}$ stimulated SHBG production $(P<0 \cdot 001)$, and that $\mathrm{T}_{4}$ was more effective than $\mathrm{T}_{3}$ (Fig. 1A). In addition, the amount of SHBG mRNA was clearly increased in relation to the cyclophilin A mRNA control in HepG2 cells after 5 days treatment with $\mathrm{T}_{4}$, but this was not as obvious after treatment with $\mathrm{T}_{3}$ (Fig. 1B).

The effect of $\mathrm{T}_{4}$ on $S H B G$ gene expression in HepG2 cells was then studied over a 3-day treatment period during which $100 \mathrm{nM} \mathrm{T}_{4}$ was added daily to the cultures, coincident with the collection of culture media for measurements of SHBG production rates (Fig. 1C). This demonstrated that the $\mathrm{T}_{4}$-induced increases in SHBG production are only apparent $(P<0.05)$ after 2 days of treatment, and increase substantially between treatment days 2 and $3(P<0 \cdot 001)$. We also explored the possibility that the delayed response to thyroid hormone in HepG2 cells might be due to an increase in TR expression, but within the time frame of our experiments in which HepG2 cells were treated with $\mathrm{T}_{4}$ there was no change in their TR1- $\alpha$ mRNA levels, as assessed by RT-PCR (Fig. 1D).

We next examined whether $\mathrm{T}_{4}(100 \mathrm{nM})$ treatments influence SHBG production by HepG2 cells over a 5-day period when the cells were cultured in high concentrations of glucose. This demonstrated that $\mathrm{T}_{4}$ increased SHBG production by HepG2 cells regardless of whether they were maintained in the presence of $100 \mu \mathrm{M}$ glucose (control) or $10 \mathrm{mM}$ glucose, added as daily supplements (Fig. 1E).

\section{Human SHBG promoter lacks a TRE and only responds in HepG2 cells after several days pre-treatment with $T_{4}$}

We have previously demonstrated that the $803 \mathrm{bp}$ human $S H B G$ promoter, which controls its activity in the liver, is influenced by a polymorphic TAAAA repeat sequence in the distal promoter sequence (Hogeveen et al. 2001) as well as a Sp1 site (Fig. 2A). However, when these upstream sequences are removed, the proximal $299 \mathrm{bp}$ promoter sequence is not only generally more active in HepG2 cells (Jänne \& Hammond 1998), but also retains its responsiveness to changes in metabolic state (Selva et al. 2007), or to treatments with drugs that act via the peroxisome proliferator receptor $\gamma$ that binds to the DR-1 element in the $299 \mathrm{bp}$ human 
$S H B G$ promoter and represses its transcriptional activity (Selva \& Hammond 2009). This DR-1 sequence can also bind HNF- $4 \alpha$ as well as COUP-TF, but does not appear to have much influence on the basal transcriptional activity of the human $S H B G$ promoter in HepG2 cells

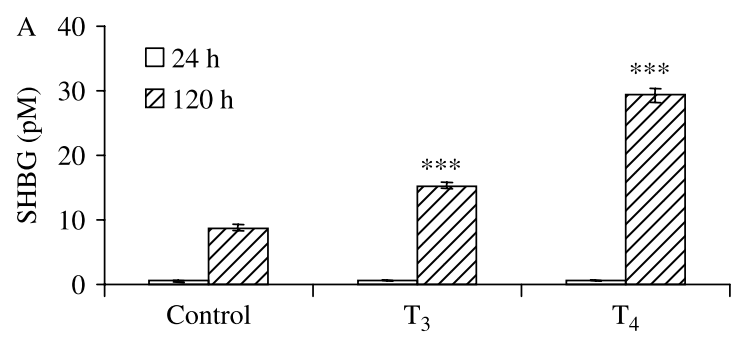

$\mathrm{B}$
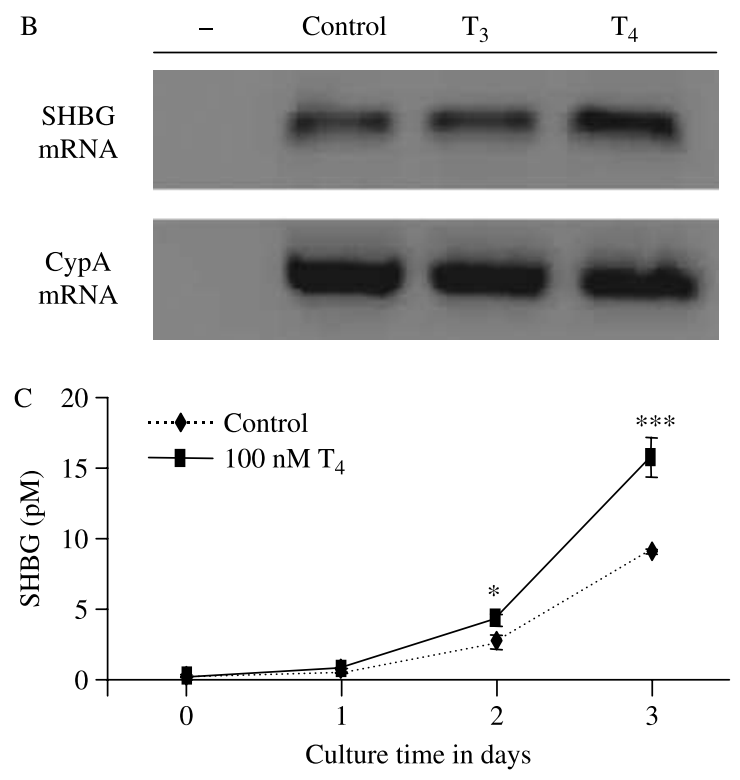

$\mathrm{D}$
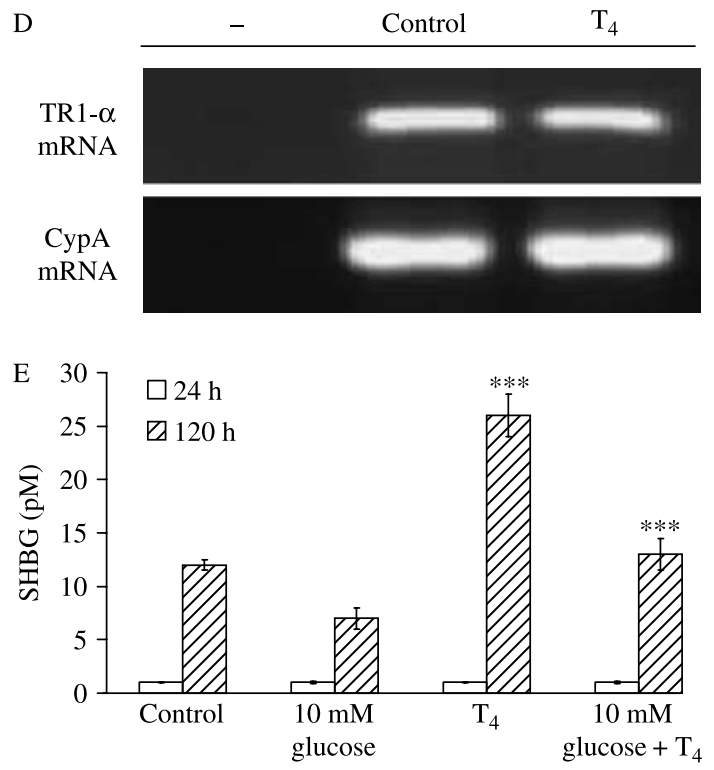

( Jänne \& Hammond 1998). By contrast, the 'TATA-less' human SHBG promoter (Jänne \& Hammond 1998) contains another binding site for HNF- $4 \alpha$ and COUP$\mathrm{TF}$, which is located in the position where a TATA box would normally be positioned (Fig. 2A), and this appears to serve as the major on-off switch for SHBG transcription: such that occupancy of this site by HNF- $4 \alpha$ promotes transcription while COUP-TF binding represses transcription (Jänne \& Hammond 1998, Selva et al. 2007). The $299 \mathrm{bp}$ human SHBG promoter sequence also contains a binding site for USF transcription factors (Fig. 2A) that play a key role in controlling the expression of the $S H B G$ gene in testicular cell types, but has no obvious role in hepatocytes (Selva et al. 2005).

Although an analysis of the 803 bp human $S H B G$ promoter failed to identify a sequence that resembles a typical TRE (Zhang \& Lazar 2000), a DR-8 sequence that has been reported to function as an atypical TRE (Bouterfa et al. 1995) overlaps the DR-1 element within the $299 \mathrm{bp} S H B G$ proximal promoter (Fig. 2A). However, the half-site of this DR-8 sequence extends outside the DNase 1 footprinted region in which this DR-1 element is located (Jänne \& Hammond 1998).

Since we found that $\mathrm{T}_{4}$ was clearly more effective than $\mathrm{T}_{3}$ in increasing SHBG production by HepG2 cells (Fig. 1), we used $\mathrm{T}_{4}$ to treat HepG2 cells in subsequent experiments to explore its mechanism of action. When the activities of the 803 and $299 \mathrm{bp}$ human $S H B G$ promoter sequences were tested in the context of a luciferase reporter gene assay after treatment with

Figure 1 Increases in human SHBG production by HepG2 cells occur after 2 days treatment with thyroid hormone. (A) HepG2 cells were cultured in medium containing FBS for 5 days and treated daily with or without $100 \mathrm{nM} \mathrm{T}_{3}$ or $\mathrm{T}_{4}$. Accumulation of human SHBG in the medium was measured using an immunofluorometric assay. Data points are shown as mean \pm s.D. of triplicates. ${ }^{\star \star \star} P<0.001$ compared with the control. (B) Semiquantitative RT-PCR analysis of SHBG mRNA levels in HepG2 cells cultured for 5 days with daily addition of $100 \mu \mathrm{M}$ glucose and PBS vehicle (control), $100 \mathrm{nM} \mathrm{T}_{3}$ or $\mathrm{T}_{4}(100 \mathrm{nM})$. Cyclophilin A (CypA) mRNA was amplified as an internal control. The negative control for the RT-PCR (-) lacked RNA template. (C) HepG2 cells were cultured in medium containing FBS for 3 days and treated daily with thyroid hormone (100 $\mathrm{nM} \mathrm{T}_{4}$ in PBS) or PBS control. Accumulation of human SHBG in the medium was measured every $24 \mathrm{~h}$ using an immunofluorometric assay. Data points are mean \pm s.D. of triplicate measurements. ${ }^{\star} P<0.05$ and ${ }^{\star \star \star} P<0.001$ compared with the control. (D) Semi-quantitative RT-PCR analysis of TR1- $\alpha$ mRNA levels in HepG2 cells cultured for 5 days with PBS vehicle (control) or $100 \mathrm{nM} \mathrm{T}_{4}$. Cyclophilin A (CypA) mRNA was amplified as an internal control. The negative control (-) lacked RNA template. (E) HepG2 cells were cultured in medium containing FBS for 5 days and treated daily with $100 \mu \mathrm{M}$ glucose (control) or $10 \mathrm{mM}$ glucose in the presence or absence of $100 \mathrm{nM} \mathrm{T}_{4}$. Accumulation of human SHBG in the medium was measured using an immunofluorometric assay. Data points are shown as mean \pm S.D. of triplicates. ${ }^{\star \star *} P<0.001$ compared with the control. 
A
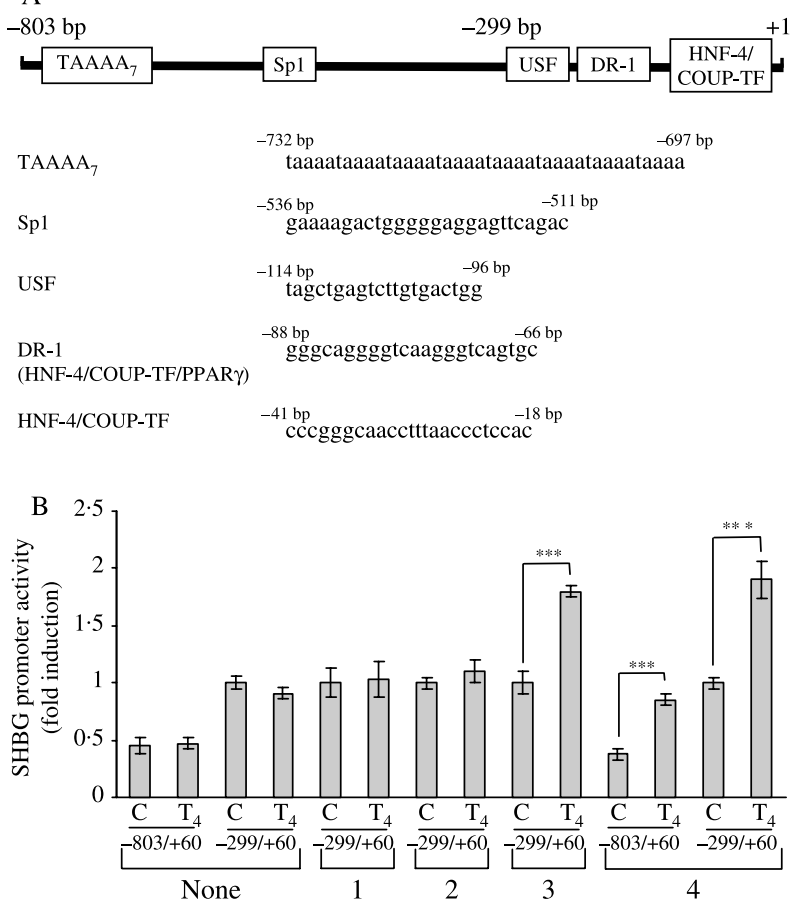

Days of pre-treatment with $100 \mathrm{nM} \mathrm{T}_{4}$ daily

Figure 2 Human SHBG promoter only responds to thyroid hormone after a 3-4 day pre-treatment. (A) The SHBG promoter sequence contains several cis elements that are footprinted by liver nuclear proteins ( Jänne \& Hammond 1998) and their relative positions within the 803 bp promoter sequence are shown as boxes, with their actual sequences listed below together with the identities of their known binding proteins ( Jänne \& Hammond 1998, Selva et al. 2005, Selva \& Hammond 2009). (B) The effect of daily addition of $100 \mathrm{nM}$ $\mathrm{T}_{4}$ on human $S H B G$ promoter activity was analyzed in HepG2 cells in the context of a luciferase reporter gene assay. Two different promoter sequences $(-803 /+60)$ and $(-299 /+60)$ were analyzed. Data points are mean \pm S.D. of triplicate measurements. ${ }^{\star \star \star} P<0.001$ compared with the control $(\mathrm{C})$.

$100 \mathrm{nM} \mathrm{T}_{4}$ for $24 \mathrm{~h}$, we observed no differences when compared with their activities in untreated HepG2 cells (Fig. 2B). We therefore examined the 299 bp $S H B G$ promoter activity in HepG2 cells pre-treated daily for 1-4 days with $100 \mathrm{nM} \mathrm{T}_{4}$ or the vehicle control. In this experiment, a significant difference (twofold, $P<0 \cdot 001)$ in the relative luciferase activity was only observed in cells pre-treated with $\mathrm{T}_{4}$ for 3 or 4 days (Fig. 2B). A similar increase in the activity of the $803 \mathrm{bp}$ promoter was observed in HepG2 cells after a 4-day pre-treatment with $100 \mathrm{nM} \mathrm{T}_{4}$ (Fig. 2B).

\section{Thyroid hormones influence hepatic SHBG production indirectly by increasing HNF-4 $\alpha$ levels}

Because HNF-4 $\alpha$ plays a key role in the transcriptional activity of the human SHBG promoter (Jänne \& Hammond 1998), we examined HNF-4 $\alpha$ mRNA levels in HepG2 cells after a 5-day treatment with $\mathrm{T}_{4}$. This indicated that the amounts of $\mathrm{HNF}-4 \alpha$ mRNA were substantially increased after treatment with $100 \mathrm{nM} \mathrm{T}_{4}$ (Fig. 3A), and that this resulted in an increase in $\mathrm{HNF}-4 \alpha$ in total cell protein extracts as well as a substantial increase in $\mathrm{HNF}-4 \alpha$ within nuclear extracts, as demonstrated by western blotting (Fig. 3B). To confirm that this effect of thyroid hormone on increasing the production of SHBG is associated with an increase in hepatic HNF-4 $\alpha$ levels in vivo, we treated mice expressing a human $S H B G$ transgene in the liver with $\mathrm{T}_{3}$ by adding it to their drinking water. This almost doubled the plasma levels of human SHBG $(P<0 \cdot 05)$ after 5 days of $\mathrm{T}_{3}$ treatment (Fig. $4 \mathrm{~A}$ ), and resulted in a similar increase in hepatic HNF-4 $\alpha$ levels $(P<0 \cdot 01)$ as assessed by western blotting (Fig. 4B).

In order to demonstrate that the thyroid hormone effect on $S H B G$ expression in HepG2 cells is mediated through increasing HNF-4 $\alpha$ levels, we pre-treated the cells daily for 4 days with or without $100 \mathrm{nM} \mathrm{T}_{4}$, and examined the activity of the $299 \mathrm{bp}$ human $S H B G$ promoter in the context of a luciferase reporter gene assay after co-transfection with either a control siRNA or a siRNA for HNF-4 $\alpha$. The results clearly indicate that the increased $S H B G$ promoter activity seen after 4 days pre-treatment with $100 \mathrm{nM} \mathrm{T}_{4}$ can be abrogated $(P<0.001)$ by treatment with the siRNA for HNF-4 $\alpha$ (Fig. 5A). As expected, the siRNA for HNF-4 $\alpha$ also reduced $S H B G$ promoter activity in untreated HepG2 cells $(P<0 \cdot 01)$, but the magnitude of the decrease was less than that seen it the $\mathrm{T}_{4}$-treated cells (Fig. 5A). As a control for the effectiveness of the siRNA treatment,

A

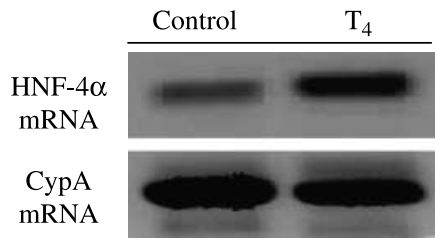

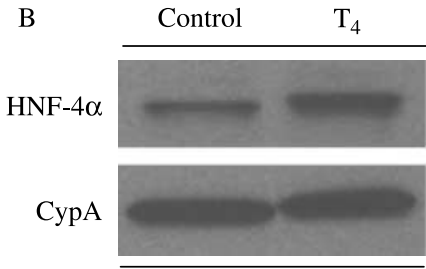

Total cell protein

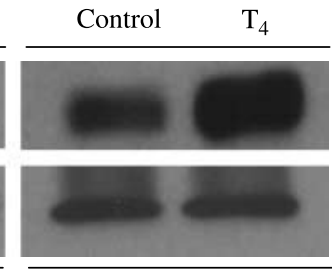

Nuclear protein extract
Figure 3 Thyroid hormone increases HNF- $4 \alpha$ mRNA and HNF- $4 \alpha$ levels in HepG2 cells. (A) Semi-quantitative RT-PCR analysis of HNF- $4 \alpha$ mRNA levels in HepG2 cells cultured for 5 days and treated daily with $100 \mathrm{nM} \mathrm{T}_{4}$ or PBS as vehicle control. Cyclophilin A (СурA) mRNA was amplified as an internal control. (B) Western blot of HNF- $4 \alpha$ and cyclophilin A in total cell protein and nuclear protein extracts of HepG2 cells harvested after the 5-day treatment period with PBS (control) or $100 \mathrm{nM} \mathrm{T}_{4}$. 

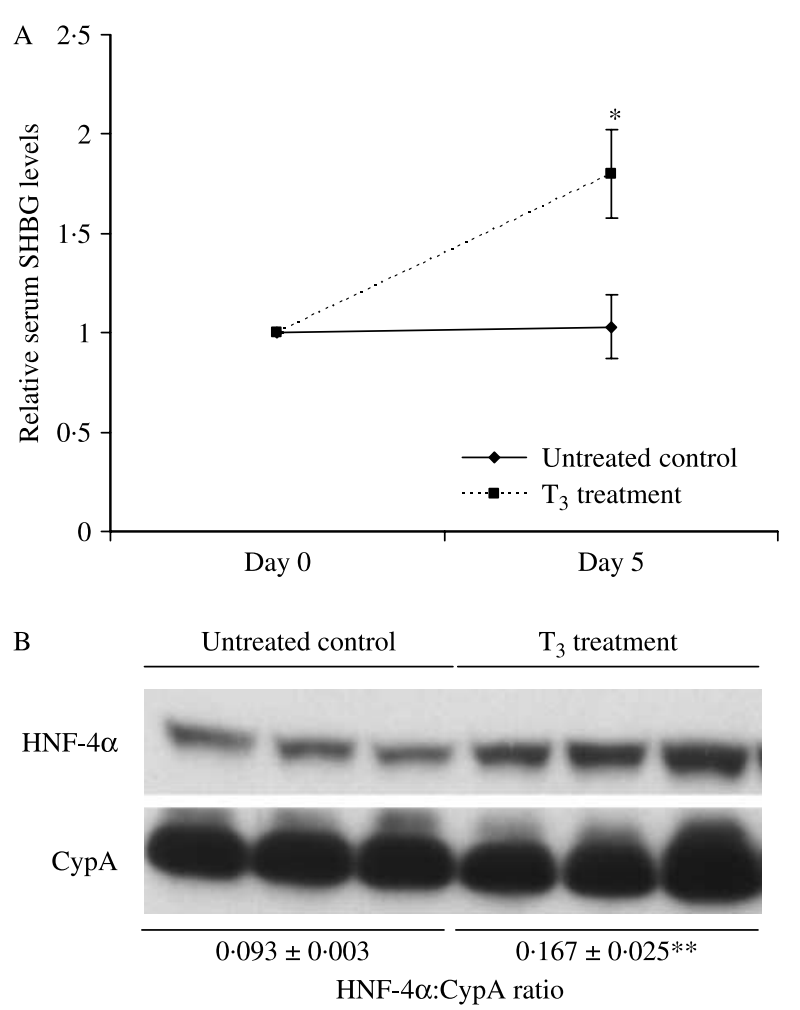

Figure 4 Treatment with $T_{3}$ increases plasma levels of human SHBG in mice that express a human SHBG transgene $(A)$ in concert with an increase in hepatic HNF-4 $\alpha$ levels (B). Female mice were either untreated $(n=3)$ or treated with $\mathrm{T}_{3}(0.5 \mathrm{mg} / \mathrm{l})$ in the drinking water $(n=3)$ for 5 days. Blood samples for measurements of blood levels of human SHBG (Selva et al. 2007) were taken on the day $T_{3}$ treatment began and on day 5 , when livers were taken for protein extraction and measurements of HNF- $4 \alpha$ levels by western blotting using cyclophilin A (CypA) as a housekeeping reference protein (Selva et al. 2007). ${ }^{\star \star} P<0 \cdot 01$.

western blots from nuclear extracts of cells treated under the same conditions reveal a substantial increase in nuclear HNF-4 $\alpha$ protein levels when the HepG2 cells were treated with $100 \mathrm{nM}$ of $\mathrm{T}_{4}$, while treatment with siRNA for HNF- $4 \alpha$ reduces the protein levels of HNF- $4 \alpha$ in cells pre-treated with either the vehicle control or $100 \mathrm{nM} \mathrm{T}_{4}$ (Fig. 5B).

\section{Inhibition of $\beta$-oxidation blocks the thyroid hormone effect on SHBG production and HNF-4 $\alpha$ levels in HepG2 cells}

Recently, we have demonstrated that HNF- $4 \alpha$ levels in HepG2 cells decrease in response to increased lipogenesis and cellular palmitate levels, and that this leads to a reduction in $S H B G$ gene expression (Selva et al. 2007). We therefore measured the palmitate content of HepG2 cells treated for 5 days with $100 \mathrm{nM} \mathrm{T}$ versus untreated cells, and found lower levels of palmitate in the $\mathrm{T}_{4}$-treated cells $\left(4 \cdot 0 \mu \mathrm{g} / 10^{6}\right.$ cells $)$, when compared with the untreated cells $\left(6 \cdot 4 \mu \mathrm{g} / 10^{6}\right.$ cells $)$. Since thyroid hormones increase metabolic rate and influence cellular levels of carnitine palmitoyltransferase I (CPTI), the rate-controlling enzyme in the fatty acid oxidation pathway (McGarry \& Brown 1997), we performed an experiment in which HepG2 cells were treated with $100 \mathrm{nM}$ of $\mathrm{T}_{4}$ or vehicle control alone or in the presence of etomoxir, a CPTI inhibitor (Murthy \& Pande 1990). This showed that treatment with 5 or $10 \mu \mathrm{M}$ etomoxir did not influence SHBG production by control cells, but reduced $(P<0.05$ and $P<0.01$ respectively) the increase in SHBG production by $\mathrm{T}_{4^{-}}$ treated HepG2 cells (Fig. 6A), as well as the increase in HNF- $4 \alpha$ protein levels that occurs in response to $T_{4}$ treatment (Fig. 6B).

\section{Discussion}

$\mathrm{T}_{4}$ increases the production and secretion of SHBG by HepG2 cells, and this response is only apparent after 2-5 days of treatment, as reported previously (Rosner et al. 1984). In our experiments, equimolar amounts of $\mathrm{T}_{4}$ were consistently more effective than $\mathrm{T}_{3}$ in these in vitro experiments, and this may be due to differences in their transport into cells in culture when compared with the liver in vivo, as well as differences in their metabolism in HepG2 cells versus normal hepatocytes. By contrast, our experiments using a transgenic mouse
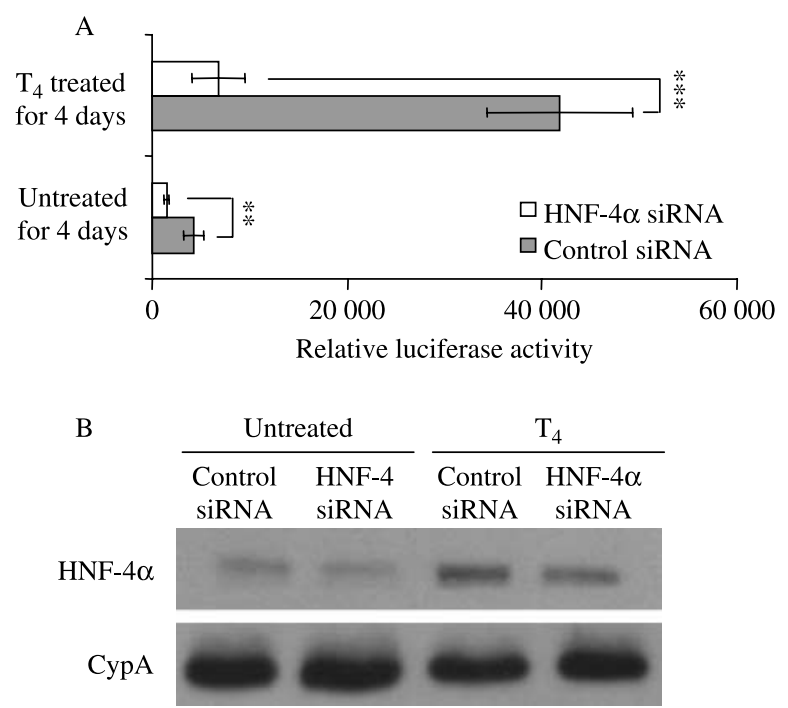

Figure 5 HNF- $4 \alpha$ siRNA treatment blocks the thyroid hormone increase in SHBG promoter activity. (A) Co-transfection of HepG2 cells with HNF-4 $\alpha$ siRNA reduced human $S H B G$ promoter activity in a luciferase reporter gene assay after 4 days pre-treatment with or without thyroid hormone $\left(\mathrm{T}_{4}\right.$ at $\left.100 \mathrm{nM}\right)$ when compared with a control siRNA. Data points are shown as mean \pm s.D. of triplicates. ${ }^{\star *} P<0.01$ and ${ }^{* * \star} P<0.001$ compared with the control siRNA. (B) Western blot of HNF- $4 \alpha$ and cyclophilin A (CypA) in nuclear extracts of HepG2 cells cultured as in (A). 


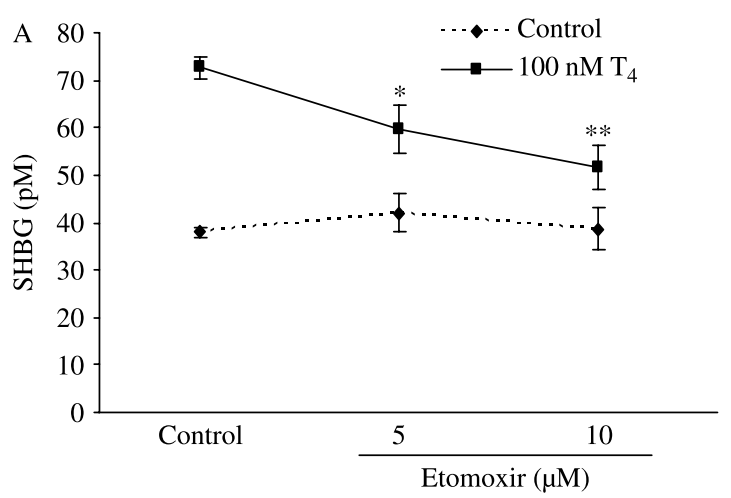

B

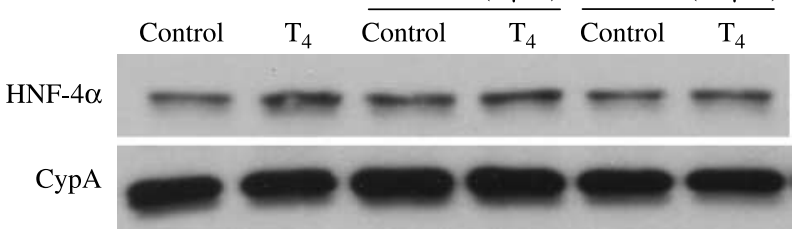

Figure 6 Thyroid hormone-induced increase in human SHBG production by HepG2 cells can be reduced by etomoxir treatment. (A) HepG2 cells were cultured in medium containing FBS for 5 days and treated daily with or without thyroid hormone $\left(T_{4}\right.$ at $100 \mathrm{nM})$ in the presence or absence of etomoxir (5 or $10 \mu \mathrm{M})$. Accumulation of human SHBG in the medium was measured using an immunofluorometric assay. Data points are shown as mean \pm s.D. of triplicates. ${ }^{*} P<0.05$ and ${ }^{* *} P<0.01$ compared with the control. (B) Western blot of HNF-4 $\alpha$ and cyclophilin A (CypA) in total protein extracts of HepG2 cells cultured for 5 days as in (A).

model (Jänne et al. 1998) indicated that treatment with $\mathrm{T}_{3}$ was much more effective than treatment with $\mathrm{T}_{4}$ in terms of increasing plasma levels of human SHBG when these hormones were added to the drinking water (data not shown), and this likely reflects the greater bioavailability of $T_{3}$ versus $T_{4}$ due to their differential binding to thyroxin-binding globulin in the blood.

To determine how $\mathrm{T}_{4}$ might influence transcription of the human $S H B G$ gene, we examined the $S H B G$ promoter sequence that controls its expression in the liver (Jänne \& Hammond 1998, Jänne et al. 1998). When analyzed in the context of a luciferase reporter gene assay in HepG2 cells, the activity of the $803 \mathrm{bp}$ 'full-length' human $S H B G$ promoter is consistently lower than that of the $299 \mathrm{bp}$ 'proximal' promoter sequence, and this has been attributed to the effects of upstream binding sites for Sp1 and a TAAAA pentanucleotide repeat on transcription (Jänne \& Hammond 1998, Hogeveen et al. 2001). Consistent with the time-dependent effects of thyroid hormone on the secretion of SHBG from HepG2 cells, the fulllength (803 bp) and proximal (299 bp) human $S H B G$ promoter sequences failed to respond acutely to thyroid hormone treatments, but they both exhibit robust responses after cells are pre-treated with $\mathrm{T}_{4}$ for 3-4 days.
Most importantly, these results demonstrate that the effect of thyroid hormone on $S H B G$ gene expression only requires sequences within the proximal promoter, and we found this to be remarkable because it lacks a typical TRE. Moreover, the fact that the $S H B G$ promoter failed to respond to either $\mathrm{T}_{3}$ or $\mathrm{T}_{4}$ within $48 \mathrm{~h}$ suggests that the thyroid hormone-induced increase in $S H B G$ gene expression is mediated indirectly through some other mechanism, and we excluded the possibility that this might involve thyroid hormone-mediated changes in the expression of the TR itself.

We have recently found that the human $S H B G$ gene in HepG2 cells, as well as in a transgenic mouse model, responds to changes in metabolic state brought about by increased lipogenesis after treatment with glucose or fructose (Selva et al. 2007). Importantly, these studies demonstrated that this effect is mediated by alterations in cellular HNF-4 $\alpha$ levels, which acts as a key regulator of SHBG transcription (Jänne \& Hammond 1998). Since HNF- $4 \alpha$ responds to and modulates the metabolic state of the liver (Sladek 1993, Jump 2004), and because thyroid hormones increase the basal metabolic rate of the liver (Malik \& Hodgson 2002), we explored the possibility that the changes in $S H B G$ expression in HepG2 cells after 5 days treatment with thyroid hormones involves changes in HNF- $4 \alpha$ expression and/or its accumulation. Our results support this because we observed an increase in cellular HNF- $4 \alpha$ mRNA content, as well as an increase in nuclear HNF-4 $\alpha$ levels, in concert with an increase in SHBG mRNA levels after the cells were treated with $\mathrm{T}_{4}$, and the $\mathrm{T}_{4}$-mediated increase in SHBG production by HepG2 cells occurs regardless of whether the cells were cultured in the presence of low or high levels of glucose. We also found that the addition of $T_{3}$ to the drinking water of mice that express a human $S H B G$ transgene in their liver results in an increase in the blood levels of human SHBG in these mice, and that this occurs in parallel with an increase in hepatic HNF-4 $\alpha$ levels in the same animals. While there is no evidence that thyroid hormones directly regulate the $H N F-4 \alpha$ gene in the liver, a change in the metabolic state of the liver after $\mathrm{T}_{4}$ treatment could in turn influence $H N F-4 \alpha$ expression.

The essential role of HNF- $4 \alpha$ in enhancing $S H B G$ transcription in HepG2 cells in response to thyroid hormones was demonstrated by blocking the increase in cellular HNF- $4 \alpha$ levels by using a siRNA approach. It was considered important to do this because thyroid hormones could increase the expression of other transcription factors that might influence $S H B G$ expression, or coactivators, such as Trp-3, PGC-1 $\alpha$, Src-1, and Src-3 (Zhang \& Lazar 2000) that influence the activities of transcription factors, including HNF-4 $\alpha$ (Wang et al. 1998, Yoon et al. 2001, Iwahashi et al. 2002). We therefore also studied the effects of the thyroid hormone treatments on the levels of Trp-3, PGC- $1 \alpha$, 
and Src-3 mRNA levels in the HepG2 cells, and failed to observe any changes in semi-quantitative RT-PCR assays (data not shown). Moreover, our results imply that the effect of thyroid hormone on human $S H B G$ expression is entirely due to the increase in HNF- $4 \alpha$ levels, because siRNA suppression of the $\mathrm{T}_{4}$-induced HNF- $4 \alpha$ levels in HepG2 cells completely blocked the $\mathrm{T}_{4}$-induced increase in $S H B G$ promoter activity.

It is possible that HNF-4 $\alpha$ levels in HepG2 cells are also influenced by their overall metabolic state because we have previously observed that HNF-4 $\alpha$ levels are reduced in concert with increases in the cellular content of palmitate after treatment of HepG2 cells with either monosaccharides or palmitoyl CoA (Selva et al. 2007). Our present experiments further support this by showing that a reduction in cellular palmitate levels after $T_{4}$ treatment occurs in concert with an increase in HNF- $4 \alpha$ levels. It is also known that thyroid hormones increase the expression of CPTI (Mynatt et al. 1994), and this likely explains the reduced palmitate levels in HepG2 cells treated with $\mathrm{T}_{4}$. Taken together therefore, these observations have led us to conclude that the lipid content of the cells must in some way influence the production and/ or the accumulation of HNF- $4 \alpha$, which in turn plays a pivotal role in controlling $S H B G$ gene expression. This is further supported by our experiment in which HepG2 cells were treated with $\mathrm{T}_{4}$ in the presence or absence of a CPTI inhibitor to block palmitate oxidation, which resulted in a loss of the thyroid hormone stimulated increase in HNF- $4 \alpha$ levels and a concomitant reduction in production of SHBG by HepG2 cells.

In conclusion, our studies demonstrate that the wellknown effect of thyroid hormones on increasing plasma SHBG levels reflects an alteration in the metabolic state of hepatocytes resulting in increased nuclear HNF- $4 \alpha$ levels, which in turn act on the $S H B G$ promoter to increase its transcriptional activity. It remains to be determined whether thyroid hormones act directly or indirectly to alter $H N F-4 \alpha$ gene expression in hepatocytes, but our data do imply that changes in metabolic state contribute in part to an increase in HNF- $4 \alpha$ levels within hepatocytes treated with thyroid hormones.

\section{Declaration of interest}

The authors declare that there is no conflict of interest that would prejudice the impartiality of this scientific work.

\section{Funding}

This work was supported by a grant from the Canadian Institutes of Health Research (grant number 15261, 2008). G L Hammond is the recipient of a Tier 1 Canada Research Chair in Reproductive Health.

\section{Acknowledgements}

We thank Nathalie Pilkington for administrative assistance; Roger Dyer for performing palmitate assays; and Dr Sheila Innis for helpful discussions.

\section{References}

Anderson DC 1974 Sex-hormone-binding globulin. Clinical Endocrinology 3 69-96.

Bouterfa HL, Piedrafita FJ, Doenecke D \& Pfahl M 1995 Regulation of H1(0) gene expression by nuclear receptors through an unusual response element: implications for regulation of cell proliferation. DNA and Cell Biology 14 909-919.

Hogeveen KN, Talikka M \& Hammond GL 2001 Human sex hormonebinding globulin promoter activity is influenced by a (TAAAA) ${ }_{n}$ repeat element within an Alu sequence. Journal of Biological Chemistry 276 36383-36390.

Iwahashi H, Yamagata K, Yoshiuchi I, Terasaki J, Yang Q, Fukui K, Ihara A, Zhu Q, Asakura T, Cao Y et al. 2002 Thyroid hormone receptor interacting protein 3 (trip3) is a novel coactivator of hepatocyte nuclear factor-4 $\alpha$. Diabetes 51 910-914.

Jänne M \& Hammond GL 1998 Hepatocyte nuclear factor-4 controls transcription from a TATA-less human sex hormone-binding globulin gene promoter. Journal of Biological Chemistry $\mathbf{2 7 3}$ 34105-34114.

Jänne M, Deol HK, Power SGA, Yee S-P \& Hammond GL 1998 Human sex hormone-binding globulin gene expression in transgenic mice. Molecular Endocrinology 12 123-136.

Jump DB 2004 Fatty acid regulation of gene transcription. Critical Reviews in Clinical Laboratory Sciences 41 41-78.

Kester MHA, Kuiper GGJM, Versteeg R \& Visser TJ 2006 Regulation of type III iodothyronine deiodinase expression in human cell lines. Endocrinology $1475845-5854$.

Leger J, Forest MG \& Czernichow P 1990 Thyroid hormones influences sex steroid binding protein levels in infancy: study in congenital hypothyroidism. Journal of Clinical Endocrinology and Metabolism 71 1147-1150.

Malik R \& Hodgson H 2002 The relationship between the thyroid gland and the liver. Quarterly Journal of Medicine 95 559-569.

McGarry JD \& Brown NF 1997 The mitochondrial carnitine palmitoyltransferase system. From concept to molecular analysis. European Journal of Biochemistry 244 1-14.

Mercier-Bodard C, Nivet V \& Baulieu E-E 1991 Effects of hormones on SBP mRNA levels in human cancer cells. Journal of Steroid Biochemistry and Molecular Biology 40 777-785.

Murthy MSR \& Pande SV 1990 Characterization of a solubilized malonyl-CoA-sensitive carnitine palmitoyltransferase from the mitochondrial outer membrane as a protein distinct from the malonyl-CoA-insensitive carnitine palmitoyltransferase of the inner membrane. Biochemical Journal 268 599-604.

Mynatt RL, Park EA, Thorngate FE, Das HK \& Cook GA 1994 Changes in carnitine palmitoyltransferase-I mRNA abundance produced by hyperthyroidism and hypothyroidism parallel changes in activity. Biochemical and Biophysical Research Communications 201 932-937.

Niemi S, Mäentausta O, Bolton NJ \& Hammond GL 1988 Timeresolved immunofluorometric assay of human sex-hormone binding globulin. Clinical Chemistry 34 63-66.

Raggatt LE, Blok RB, Hamblin PS \& Barlow JW 1992 Effects of thyroid hormone on sex hormone-binding globulin gene expression in human cells. Journal of Clinical Endocrinology and Metabolism 75 116-120.

Rosner W, Aden DP \& Khan MS 1984 Hormonal influences on the secretion of steroid-binding proteins by a human hepatoma-derived cell line. Journal of Clinical Endocrinology and Metabolism 59 806-808.

Sarne DH, Refetoff S, Rosenfield RL \& Farriaux JP 1988 Sex hormonebinding globulin in the diagnosis of peripheral tissue resistance to 
thyroid hormone: the value of changes after short term triiodothyronine administration. Journal of Clinical Endocrinology and Metabolism 66 740-746.

Selva DM \& Hammond GL 2009 Peroxisome-proliferator receptor $\gamma$ represses hepatic sex hormone-binding globulin expression. Endocrinology 150 2183-2189.

Selva DM, Hogeveen KN \& Hammond GL 2005 Repression of the human sex hormone-binding globulin gene in Sertoli cells by upstream stimulatory transcription factors. Journal of Biological Chemistry 280 4462-4468.

Selva DM, Hogeveen KN, Innis SM \& Hammond GL 2007 Monosaccharide-induced lipogenesis regulates the human hepatic sex hormone-binding globulin gene. Journal of Clinical Investigation 117 3979-3987.

Sladek FM 1993 Orphan receptor HNF-4 and liver-specific gene expression. Receptor 3 223-232.

van Stralen PG, van der Hoek HJ, Docter R, De Jong M, Krenning EP, Everts ME \& Hennemann G 1996 Uptake and metabolism of 3,5,3'-triiodothyronine and 3,3', $5^{\prime}$-triiodothyronine by human liver-derived cells: HepG2 cells as a model for thyroid hormone handling by human liver. Journal of Clinical Endocrinology and Metabolism 81 244-248.

Wang JC, Stafford JM \& Granner DK 1998 SRC-1 and GRIP1 coactivate transcription with hepatocyte nuclear factor 4. Journal of Biological Chemistry 273 30847-30850.

Yoon JC, Puigserver P, Chen G, Donovan J, Wu Z, Rhee J, Adelmant G, Stafford J, Kahn CR, Granner DK et al. 2001 Control of hepatic gluconeogenesis through the transcriptional coactivator PGC-1. Nature 413 131-138.

Zhang J \& Lazar MA 2000 The mechanism of action of thyroid hormones. Annual Review of Physiology 62 439-466.

Received in final form 25 March 2009

Accepted 25 March 2009

Made available online as an Accepted Preprint 31 March 2009 